\title{
PERANCANGAN SISTEM INFORMASI PENDAFTARAN PASIEN RAWAT JALAN BERBASIS VISUAL BASIC 6.0 DI RUMAH SAKIT UMUM MADANI MEDAN TAHUN 2018
}

\author{
1. Ary Syahputra Wiguna; ${ }^{2}$ Dhea Yola Mahesa Nasution \\ ${ }^{1 .}$ Dosen APIKES Imelda, Jalan Bilal Nomor 52 Medan; '2.Alumni APIKES Imelda \\ E-mail: ${ }^{1 .}$ aryesyah1@gmail.com
}

\begin{abstract}
ABSTRAK
Kecanggihan teknologi komputer pada saat ini telah mendominisasi dalam hal pekerjaan termasuk dalam pengarsipan data-data dan kebutuhan pengelolahan data untuk memenuhi kebutuhan di RSU Madani Medan, dimana dalam menyajikan informasi pendaftaran pasien rawat jalan masih dengan cara pencatatan. Penulis mencoba mengembangkan suatu sistem yang baru yang dapat digunakan sebagai alternative pemecahan masalah yang sering terjadi yaitu dengan bantuan komputer yang telah dilengkapi dengan aplikasi yang dibutuhkan. Pada dasarnya sistem yang telah berjalan telah terlaksana dengan baik hanya saja perlu dilakukan beberapa perbaikan dimana sistem yang sedang berjalan membutuhkan penyimpanan data-data yang cukup banyak. Perbaikan yang dimaksud adalah peralihan dari sistem pencatatan ke sistem informasi yang berbasis komputer. Tujuan dari perbaikan tersebut untuk mempercepat proses pengolahan data sehingga pada saat data dibutuhkan dapat diperoleh dengan cepat dan informasi yang dihasilkan benar-benar akurat. Kesimpulannya akan dibuat suatu sistem komputerisasi yang populer yaitu pemograman Visual Basic 6.0, Visual Basic merupakan salah satu Development Tool untuk membuat berbagai macam program komputer dan untuk pembuatan laporan data-data dengan menggunakan Crystal Report.
\end{abstract}

Kata Kunci: Visual Basic 6.0, Perancangan Sistem Informasi Pendaftaran Pasien Rawat Jalan

\begin{abstract}
The sophistication of computer technology at this time has been dominating in terms of work included in data archiving and data management needs to meet the needs at RSU Madani Medan, where in presenting information on outpatient registration is still by way of recording. The author tries to develop a new system that can be used as an alternative problem solving that often happens with the help of computers that have been equipped with the required applications. Basically the system has been running well done just need to do some improvements where the system is running requires storage of data quite a lot. The improvements in question are the transition from recording systems to computer-based information systems. The purpose of these improvements to speed up the processing of data so that when the data needed can be obtained quickly and the resulting information is really accurate. The conclusion will be made a popular computerized system that is programming Visual Basic 6.0, Visual Basic is one of the Development Tool to create various computer programs and to manufacture reports data by using Crystal Report.
\end{abstract}

Keywords: Desi Visual Basic 6.0, Information System Design of Outpatient Registration Information 
Menurut WHO (World Health Organiza tion), rumah sakit adalah bagian integral dari suatu organisasi sosial dan kesehatan dengan fungsi menyediakan pelayanan paripurna (komprehensif), penyembuhan penyakit (kur atif) dan pencegahan penyakit (preventif)

kepada masyarakat. Rumah sakit juga merupakan pusat pelatihan bagi tenaga kesehatan dan pusat penelitian medis. Berdasarkan undang-undang No. 44 Tahun 2009 tentang rumah sakit, yang dimaksudka $\mathrm{n}$ dengan rumah sakit adalah institusi pelaya nan kesehatan yang menyelenggarakan pelayanan kesehatan perorangan secara paripurna yang menyediakan pelayanan rawat inap, rawat jalan, dan gawat darurat (Wordpress, 2010).

Kecanggihan teknologi komputer pada saat ini telah mendominisasi dalam hal pekerjaan termasuk dalam pengarsipan datadata dan kebutuhan pengolahan data untuk memenuhi kebutuhan informasi tersebut. Berbagai program komputer yang telah dibuat dengan menggunakan database dalam melakukan pengarsipan data-data membuat pekerjaan menjadi semakin mudah sehingga banyak rumah sakit yang menggunakan program dalam pengarsipan data-data dengan konsep basis data dibandingkan manual. Namun dalam pembuatan program tersebut tidaklah sederhana penggunaannya sehingga banyak programmer yang masih mengalami kesulitan dalam membuat model, melakukan analisis, serta menyusun rancangan basis data yang optimal (Edhy Sutanta, 2011).

Melihat situasi tersebut, sudah sangatla $\mathrm{h}$ tepat jika rumah sakit menggunakan sisi kemajuan komputer, baik perangkat lunak maupun perangkat kerasnya dalam upanya membantu penanganan manajemen yang sebelumnya dilakukan secara manual. Alat bantu yang dapat mendukung adalah dengan menggunakan program komputer, yang sala $\mathrm{h}$ satunya yaitu dengan menggunakan progra $\mathrm{m}$ Microsoft Visual Basic 6.0.

Visual Basic 6.0 merupakan salah satu bahasa program Komputer yang cukup populer. Bahasa pemprograman Visual Basic , yang dikembangkan oleh Microsoft sejak tahun 1991, merupakan pengembangan dari pendahulunya yaitu bahasa pemprograman
BASIC(Beginner's All-Purpose Symbolic Instruction Code) yang dikembangkan pada era 1950-an.

Visual Basic merupakan salah satu Development Tool yaitu alat bantu untuk membuat berbagai macam program Komput er, khususnya yang menggunakan system operasi Windows. Selain itu juga, Visual Basic merupakan salah satu bahasa pemprog raman Komputer yang mendukung object $(O$ bject Oriented Programming $=O O P$ ), (Mary anto, 2011). Berbagai pengalaman di rumah sakit yang menggunakan sistem pengolahan data secara manual menunjukkan banyaknya kehilangan memperoleh laba atau keuntunga $\mathrm{n}$ akibat kurangnya dukungan informasi yan g cepat, tepat, akurat,dan terintegrasi dengan baik.

Berdasarkan survey awal yang penulis peroleh dari staf pegawai rekam medis di RSU Madani Medan bahwa sistem informasi pendaftaran pasien terkhususkan dengan pendaftaran pasien rawat jalan perlu pengem bangan dari sistem yang sebelumnya. Oleh $\mathrm{k}$ arena itu penulis berusaha mengembangkan dan merancang sistem baru yang berbasis Visual Basic 6.0.

\section{Perumusan Masalah}

Berdasarkan latar belakang diatas, maka rumusan masalah dalam penilitan ini adalah "Bagaimanakah Sistem Informasi Pendaftaran Pasien Rawat Jalan di RSU Madani tahun 2018?”.

\section{Tujuan penelitian}

1. Peneliti merancang sistem pendaftaran yang lebih efektif dan efisien dalam pengolahan data pasien rawat jalan pada RSU Madani Medan.

\section{Manfaat Penelitian}

\section{Bagi Peneliti}

Diharapkan dalam penelitian ini dapat menerapkan teori dan praktik di lapang an mengenai penggunaan Rancangan

Sistem Pendaftaran Pasien Rawat Jalan Berbasis Visual Basic di RSU Madani Medan Tahun 2018.

2. Bagi Rumah Sakit Untuk mempermudah pegawai rumah sakit dalam pendaftaran pasien rawat 
jalan pada Rumah Sakit Madani Medan dan dengan adanya program yang dibuat dapat membantu cepatnya proses masuknya pasien rawat jalan sehingga pasien mendapatkan pelayanan dan pertolongan yang cepat dan tepat sesuai dengan harapan pasien atau masyarakat.

\section{METODE}

\section{Jenis Penelitian}

Penelitian ini adalah penelitian Deskript if yaitu metode penelitian untuk menyajikan gambaran lengkap yang dimaksudkan untuk eksplorasi dan klarifikasi mengenai suatu fenomena atau kenyataan sosial, dengan mendeksripsikan sejumlah variabel yang bekenaan dengan masalah unit yang diteliti untuk mengetahui rancangan sistem informa si pendaftaran pasien rawat jalan pada RSU Madani Medan.

\section{Waktu Penelitian}

Penelitian ini dilakukan di RSU Madani dan waktu penelitian dilaksanakan mulai bulan Juni-Juli 2018.

\section{Tempat Penelitian}

Tempat penelitian ini dilaksanakan di Rumah Sakit Umum Madani Medan yang berlokasi di Jl. A. R. Hakim No. 168, Sukar amai I, Medan area, Kota medan. Alasan peneliti melakukan penelitian di Rumah Sakit Umum Madani Medan untuk Meranca ngansistem Informasi Pendaftaran Pasien Rawat Jalan Berbasis Visual Basic 6.0

\section{Teknik Pengumpulan Data}

Sebelum proses pengumpulan data dilakukan, tahap awal dalam proses ini adalah melakukan persiapan untuk kelancara $\mathrm{n}$ pelaksanaan berupa surat izin penelitian dan penjajakan ketempat dimana penelitian akan dilakukan. Setelah persyaratan dipenuh i selanjutnya dilaksanakan proses pengambil an data dengan metode observasi.

\section{Observasi (Pengamatan)}

Peneliti melakukan pengamatan atau observasi langsung terhadap subjek penelitia n. Observasi yang saya lakukan adalah meng amati secara langsung jalannya sistem pengo lahan data dan proses kerja pegawai serta melihat format data-data pasien rawat jalan yang digunakan saat ini.

\section{Definisi Operasional}

Penerimaan pasien rawat jalan dimaksu d sebagai pelayanan yang diberikan kepada pasien yang tidak mendapatkan pelayanan rawat inap si fasilitas pelayanan kesehatan. Rawat jalan adalah pelayanan medis kepada seorang pasien untuk tujuan pengamatan, dia gnosa, rehabilitas, dan pelayanan kesehatan 1 ainnya, tanpa mengharuskan pasien tersebut dirawat inap. Rawat jalan yang dimaksud ha nya berupa pemeriksaan dan proses berjalan nya pengobatan pasien diluar dari pada tindakan lanjut rumah sakit. Namun pasien rawat jalan harus melakukan pemeriksaan ulang atau sering disebut dengan cek-up supaya pihak rumah sakit dapat mengetahui perkembangan pasien dan dapat memberika $\mathrm{n}$ tindakan selanjutnya.

\section{Instrumen Penelitian}

Perancangan sistem informasi pendaftar an rawat jalan berbasis visual basic 6.0 adalah suatu sistem yang memproses serta mengintegrasikan seluruh alur proses data pelayanan kesehatan dalam bentuk prosedur pendaftaran untuk memperoleh informasi yang cepat. Tepat, dan akurat untuk menunja ng tercapainya tujuan rumah sakit, yaitu peningkatan mutu pelayanan kesehatan di rumah sakit.

\section{Cara Pengumpulan Data}

Pengumpulan data dilakukan secara observasi, dengan cara mengamati lembar formulir Ringkasan Masuk Dan Keluar. Yang di lihat dari aspek fisik, anatomik, dan kelengkapan pengisian data.

\section{PEMBAHASAN}

Adapun hasil program yang dirancang untuk meningkatkan rekam medis dan sistem informasi pelayanan primer di RSU Madani seperti dijabarkan pada uraian berikut:

\section{Tampilan Menu Utama}

Gambar 1. Tampilan Menu Utama Program

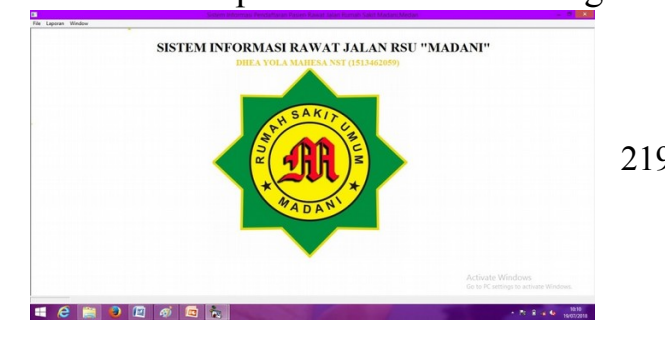




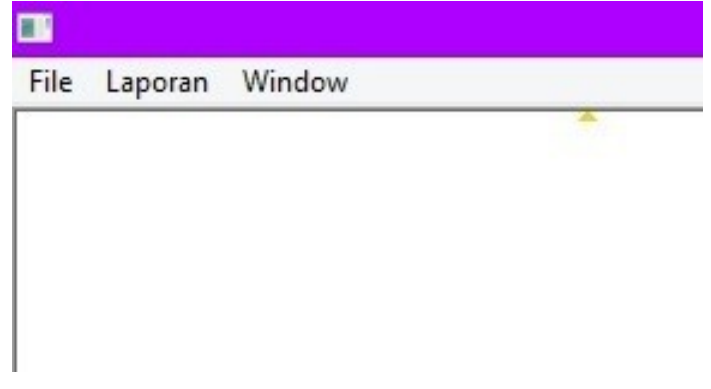

\section{Tampilan Entry Data Pasien}

Tampilan pada gambar 2 adalah form untuk menginput dan mengelola data pasien yang baru masuk.

Gambar 2. Tampilan Form Entry Data Pasie $\mathrm{n}$

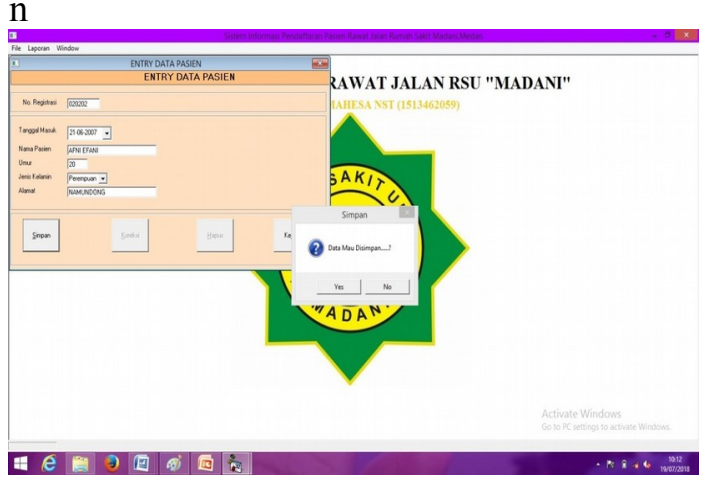

Jika dipilih salah satu opsi misalnya Cetak Data Pasien, lalu diklik tombol Cetak maka akan tampil form data pasien sesuai nomor Rekam Medis yang dipilih.

\section{Tampilan Entry Data Transaksi}

Gambar 3. Tampilan Entry Data Transaksi

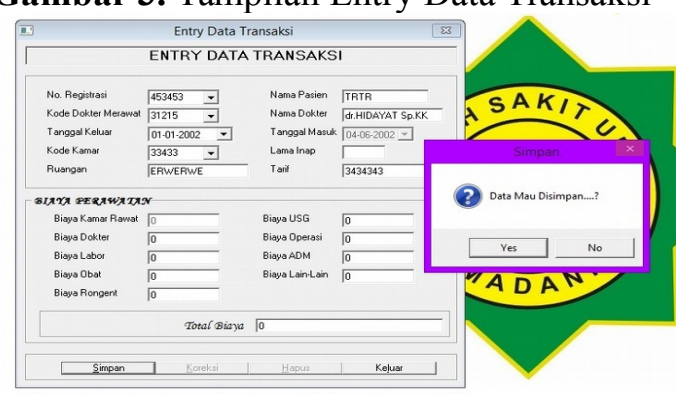

4. Tampilan Entry Data Dokter

Gambar 4. Tampilan Entry Data Dokter

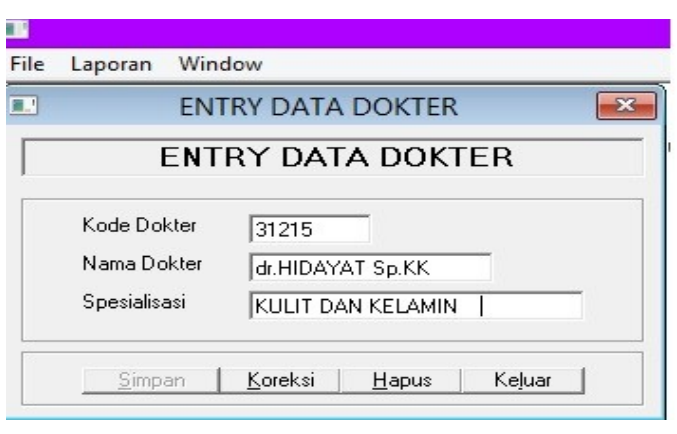

\section{5.. Laporan Rawat Jalan Pasien}

Tampilan gambar 5 adalah pilihan laporan data Pasien Rawat Jalan di RSU Madani.

Gambar 5. Tampilan Jendela Laporan Data Pasien

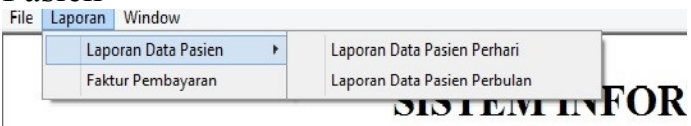

Jika dipilih salah satu opsi misalnya Cetak Data Rawat Jalan, lalu diklik tombol Cetak maka akan tampil tanggal, bulan sesuai nomor Rekam Medis yang dipilih seperti pada gambar 6 berikut:

Gambar 6. Tampilan Laporan HarianPasien

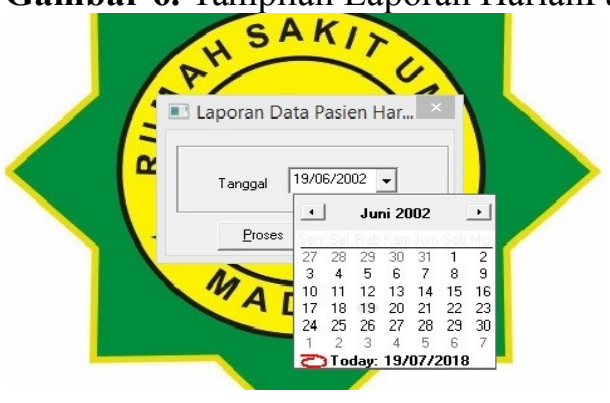

\section{KESIMPULAN}

Dari uraian pada bab-bab sebelumnya dan berdasarkan hasil penelitian dengan perancangan sistem informasi ini, maka penulis mengambil kesimpulan sebagai berikut :

1.

Sistem Informasi Rawat

Jalan di RSU Madani Medan masih bersifat manual dan komputer, bersifat manual karena dalam pencatatan pendaftaran awal berobat jika pasien baru pertama kali berkunjung ke rumah sakit dan datanya sudah tersimpan dan terdata ke komput er. Sedangkan kompute digunakan masi $\mathrm{h}$ menggunakan aplikasi Micorosft Word dan Microsoft Excel.

2. Aplikasi sistem informasi yang dirancang dapat mengelola data pasien (input, edit, hapus), data rawat jalan (input, edit, 
hapus) dan laporan (data pasien, data rawat jalan).

3. Aplikasi sistem informasi bekerja lebih cepat, efektif dan meminimalisir redundansi (duplikasi) data dibanding sistem yang sedang berjalan di RSU Madani Medan.

4.

Bahasa Pemrograman

Visual Basic merupakan bahasa pemrograman yang handal untuk merancang aplikasi berbasis database dan Microsoft Access merupakan salah satu aplikasi pengolah an database yang mudah dipelajari.

\section{SARAN}

Dari pembahasan dan hasil penelitian maka saran yang penulis sampaikan adalah sebagai berikut :

1.

Untuk meningkatkan pelayanan bagi pasien dan efektifitas kerja agar pihak RSU Madani menggunakan teknologi informasi dan sistem komputerisasi sesuai kebutuhan.

2. Bagi institusi pendidikan APIKES Imelda Medan, agar dapat meluangkan banyak waktu praktek kerja lapangan pada bagian rekam medis di lembaga pelayanan kesehatan.

3.

Bagi peneliti selanjutnya agar mencoba penelitian yang lebih luas tentang RSU Madani Medan berupa sistem komputerisasi berbasis jaringan atau berbasis web sehingga dapat membantu pihak lembaga kesehatan dalam memenuhi tingkat kepuasan pasien dan masyarakat.

\section{DAFTAR PUSTAKA}

Aprianto, Muhamad Chusnan, Aditya Lia Romadona. (2007). Teknologi Informas $i$ Kesehatan. Jakarta: Medical Book.

Departemen Kesehatan RI. (1997). Pedoman Pengolahan Rekam Medis Rumah Sakit Di Indonesia Revisi I. Jakarta: Depkes RI.

http://tintahmerah.wordpress.com/2015/ 06/23/pengertian-pasien/. Diakses pada tanggal 16 Juli 2018 Pukul 12:30 WIB.

Kadir, Abdul. (2009). Dasar Perancangan dan Implementasi Database Relasional. Yogyakarta: Andi.

Khotimah, Nurul. (2011). System developme nt life cycle. http://nurul-khotimahnurul.blogspot.com/2011/05/sdlcsystem-development-life-cycle.html? $\underline{\mathrm{m}=1}$. Diakses pada tanggal 17 Juli 2018 pukul 12:38 WIB.

Nandra. (2015). Pengertian Pasien. S.1: s.n

Sihombing, Poltak. (2011). Memulai Visual Basic 6.0. Jakarta: Erlangga.

Sutabri, Tata. (2012). Analisa Sistem Informasi. Edisi 1. Yogyakarta: Andi.

Sutanta, Edhy. (2011). Basis Data Dalam Tinjauan Konsepsual. Yogyakarta: Andi.

Wahyudi, Bambang. (2008). Konsep Sistem Informasi Dari Bit Sampai Ke Database. Edisi 1. Yogyakarta: Andi.

Yohanda. (2015). Prosedur Pelayanan Rawat Jalan. http://yohandawordpressc om.wordpress.com/2015/10/29/prosedu r-pelayana-rawat-jalan-yang-baik/amp/. Diakses pada tanggal 16 Juli 2018 pukul 13:02 WIB. 